\title{
A SUMMARY OF THE 1963 ANNUAL MEETING
}

\author{
By Dr. L. R. THIESMEYER ${ }^{1}$
}

This meeting has reviewed the many impacts on our modern life and on the profession of forestry of the new technologies applied to woods operations and management. The revolution of practices in the pulp and paper and other forest products industries has begun in the woods. Its pace has been amazingly swift, much of it coming about during the past 15-20 years. One can predict that the pace will increase and that even more remarkable changes will come during the next ten years. This is because new technology in all fields gains momentum. But, even more importantly, it will have to be so because our forest-based industries face more and stiffer competition than ever before in their history.

The revolution will have to extend also into our manufacturing operations because they have become so costly in capital plant that the return on investment has been shrinking steadily. This is because we have, through a tradition of mimicry, been sticking with archaic technology. Major changes will be more difficult to achieve at the mills, however, because they would bring obsolescence to huge and costly plants.

Now, since the growing and protection and harvesting of trees is really an integral part of the whole manufacturing operation, foresters and logging engineers have a wide-open challenge and opportunity to be of greater service and importance than ever before in speeding up the application of new technologies in the field-where it is the easiest to do. There is still more money to be saved in the woodlands end of the business than anywhere else by applying the new tools of science and engineering.

${ }^{1}$ President, Pulp and Paper Research Institute of Canada, Montreal, P.Q. 